\title{
The pilot study assessing efficacy and versatility of novel therapy for neoplastic ulceration: clinical and microbiological aspects
}

\author{
Maciej Sopata ${ }^{1}$, Elżbieta Tomaszewska ${ }^{1}$, Zygmunt Muszyński², Maria Ciupińska², Aleksandra Kotlińska-Lemieszek ${ }^{1}$ \\ 1Department of Palliative Medicine, Poznan University of Medical Sciences, Poland \\ Head: Aleksandra Kotlińska-Lemieszek, MD, PhD \\ 2Department of Pharmaceutical Bacteriology, Poznan University of Medical Sciences, Poland \\ Head: Prof. Zygmunt Muszyński \\ Postep Derm Alergol 2013; XXX, 4: 237-245 \\ DOI: 10.5114/pdia.2013.37034
}

\begin{abstract}
Introduction: Neoplastic ulcers are chronic and, most often, irreversible lesions caused by proliferation of tumor cells infiltrating and damaging skin tissues. The treatment of neoplastic ulcers is a very difficult and time-consuming process. So, is very important to find methods of controlling this type of chronic wounds.

Aim: To evaluate the efficiency of monitored treatment of neoplastic ulcers by means of providing moist wound environment dressings and antiseptic to the group of patients with an advanced stage of tumor, with particular focus on the impact of the treatment applied on the clinical condition of the ulcers; to evaluate the impact of the treatment applied on the dynamics of bacterial flora in neoplastic ulcers, with particular focus on the presence of alarm pathogens; to conduct a risk analysis of the occurrence of local and systemic complications during treatment.

Material and methods: This was a prospective pilot clinical study of 30 patients with malignant ulcers, 13 male and 17 female aged from 24 to 92 years treated with octenidine antiseptic and dressing set for 3 weeks. The wounds were clinically assessed for the changes of amount of necrotic tissue, exudate level and type, malodour and pain level during treatment. At the baseline and after 3 weeks of treatment, the wounds were swabbed for microbiological assessment.

Results: The used scheme of treatment is efficient and brings clinical improvement in all treated ulcers. During the 3 -week treatment, reduction of necrotic tissue, decrease in the level of exudate, pain and malodour was observed in all patients $(p<0.05)$. High activity of octenidine against $\operatorname{Gram}(-)$ and $\operatorname{Gram}(+)$ bacteria was observed. The use of octenidine dihydrochloride correlated with a progressing eradication of multiresistant strains and alarm pathogens $(p<0.001)$. No serious adverse effects or significant symptoms of intolerance of the applied treatment were observed.
\end{abstract}

Key words: antiseptics, octenidine, topical treatment, microbiology, cancer ulceration.

\section{Introduction}

Neoplastic ulcers are chronic and, most often, irreversible lesions caused by proliferation of tumor cells infiltrating and damaging skin tissues. The causative factors of neoplastic ulcers are primary neoplasm, tumor recurrence, metastases and, less frequently, complications after radiotherapy. Uncontrolled proliferation of neoplastic cells may lead to damage of the skin, subcutaneous and muscle tissues, and consequently bones. According to the available data, neoplastic ulcers may be present among 5\% of patients with primary neoplasm and among $10 \%$ of patients with metastatic cancer [1, 2].

Local invasion is an effect of direct infiltration of tumor cells. The early symptoms include inflammation, tissue hardening, erythema, and local increase of temperature. The skin shows characteristic discolouration, referred to as the "orange peel". Moreover, the lesion may be immobilised in relation to deeper tissues.

Address for correspondence: Maciej Sopata MD, PhD, Department of Palliative Medicine, Poznan University of Medical Sciences, Hospice Palium, Os. Rusa 25A, 61-245 Poznan, Poland, phone/fax: +48 618738 303/306, e-mail: maciej.sopata@skpp.edu.pl Received: 23.04.2013, accepted: 23.06.2013. 
Proliferation of neoplastic cells together with impairment of anticoagulation mechanisms may lead to the clotting, closure of blood vessels and ultimately to tissue necrosis [3]. Neoplastic ulcers are always colonized by bacteria of different species. The location and characteristics of malignant lesions, as well as the presence of a large amount of necrotic tissue, create a fertile environment for bacterial colonization. It is believed that the presence of aerobic (Proteus spp., Klebsiella spp., Pseudomonas spp.) and anaerobic (Bacterioides spp., Clostridium spp.) bacteria, as well as proteolytic mechanisms ongoing in necrotic tissue, are responsible for the increased level of malodour and malodorous exudate [4, 5]. Fragile and breakable blood vessels of the tumor may cause bleeding [3].

Table 1. Characteristics of patients with neoplastic ulcers $(n=30)$

\begin{tabular}{lc}
\hline Men/women & $13 / 17$ \\
\hline $\begin{array}{l}\text { Age, range, } X \pm \text { SD, } \\
\text { Me [years] }\end{array}$ & $24-92,63.2 \pm 12.2,64$ \\
\hline Primary diagnosis: & $9(30 \%)$ \\
\hline Breast cancer & $6(20 \%)$ \\
\hline Vulva cancer & $5(16.7 \%)$ \\
\hline Skin cancer & $4(13.3 \%)$ \\
\hline Head and neck cancer & $3(10 \%)$ \\
\hline Bone cancer & $3(10 \%)$ \\
\hline Other & $9(30 \%)$ \\
\hline Location of the ulcer: & $8(26.7 \%)$ \\
\hline Breast & $5(16.7 \%)$ \\
\hline Skin & $4(13.3 \%)$ \\
\hline Groin area & $4(13.3 \%)$ \\
\hline Vulva & $2.5 .12 \pm 1.18$ \\
\hline Head and neck & $6.28 \pm 0.64$ \\
\hline Duration of ulceration, \\
range, $X \pm$ SD, Me [years]
\end{tabular}

\section{Aim}

The treatment of neoplastic ulcers is a very difficult and time-consuming process. Unfortunately, the available studies of the topic are predominately conducted on small groups of patients.

Therefore, the aim of the present pilot study was: 1) to evaluate the efficiency of monitored treatment of neoplastic ulcers by means of providing moist wound environment dressings and antiseptic to the group of patients with an advanced stage of tumor, with particular focus on the impact of the treatment applied on the clinical condition of the ulcers; 2) evaluate the impact of the treatment applied on the dynamics of bacterial flora in neoplastic ulcers, with a particular focus on the presence of alarm pathogens; 3) to conduct a risk analysis of the occurrence of local and systemic complications during treatment.

\section{Material and methods \\ Group of the patients with neoplastic ulcers}

Patients with neoplastic ulcers from the Palliative Care Ward, Palliative Medicine Ambulatory, Department of Palliative Medicine, Hospice Palium in the Clinical Hospital in Poznan, Poznan University of Medical Sciences were enrolled into this study from 2009 to 2011. The group consisted of 30 patients (13 men and 17 women). All patients had one neoplastic ulceration. The mean age of the patients was $63.2 \pm 12.2$ (age range 24-92 years), median ( $\mathrm{Me})=64$ years .

At the baseline assessment, the patient body mass range was $44-136 \mathrm{~kg}$, mean body mass $54.2 \pm 12.26$ years, $\mathrm{Me}=55 \mathrm{~kg}$. The range of body mass index (BMI) was 12.4$36.2 \mathrm{~kg} / \mathrm{m}^{2}$, mean BMI $24.2 \pm 4.8 \mathrm{~kg} / \mathrm{m}^{2}, M e=24 \mathrm{~kg} / \mathrm{m}^{2}$.

The patients were treated for breast cancer $(n=9 ; 30 \%)$, vulvar cancer ( $n=6 ; 20 \%)$, skin cancer $(n=5 ; 16.7 \%)$, cancer of head and neck $(n=4 ; 13.3 \%)$, bone cancer $(n=3$; $10 \%)$, and other types of cancer $(n=3 ; 10 \%)$.

The mean duration of neoplastic ulcer was $1.8 \pm 0.7$ years, range of duration $0.2-3.8$ years, $M e=1.6$ years.

Location of ulcers: nipple -9 patients (30\%), skin -8 patients (26.7\%), inguinal region -5 patients (16.7\%), vulva -4 patients (13.3\%), regions of head and neck -4 patients (13.3\%). The Mean Performance Status of patients according to the ECOG scale was 3.5 and according to the Karnofsky scale -55 .

At the baseline assessment, blood count was performed for every patient. The level of haemoglobin ( $\mathrm{Hgb})$, proteins and albumins was assessed. The mean level of Hgb, protein and albumins and patients characteristics are given in Table 1.

\section{Patient group}

Thirty patients with advanced cancer, confirmed by the earlier histopathological examination, and neoplastic ulcers, were included in the study group. The patients were treated for 3 weeks using a dressing set and octenidine dihy- 
drochloride antiseptic as described in section Methods of clinical assessment and wound dressing used.

Patients meeting the following criteria were included in the study: time of survival longer than 2 months, neoplastic wound unsuitable for surgical treatment and not being a result of earlier radiotherapy, with no risk of massive bleeding or no documented massive bleeding during change of dressings, no clinical signs of infection, no intolerance or allergy to locally applied octenidine.

All patients included in the study were informed about the planned method of wound treatment and expressed written informed consent to the proposed treatment. The impact of the methods used on the patients clinical condition and bacteriological dynamics was as sessed at the baseline and repeated after 3 weeks. The research was approved by the Bioethical Commission of the Poznan University of Medical Sciences.

At the baseline, the performance status of the patients was assessed using ECOG and Karnofsky Performance Status Scales [6].

At the beginning and end of the treatment, an evaluation of the patients' clinical status was performed by a physician and a nurse. On the basis of the results obtained, conclusions presented in this study were formulated.

For ethical reasons and because of the specific status of patients with advanced cancer, no placebo group was formed.

\section{Methods of clinical assessment and wound dressing used}

The wounds were clinically assessed for the amount of necrotic tissue, exudate level and type, malodour and pain level.

The amount of necrotic tissue was defined as "significant" (70-100\% of wound surface), "moderate" (30$69 \%$ of wound surface), "little" (1-29\% of surface) or "lack of necrotic tissue". The level of exudate was defined as "significant" if the dressing and the patient's underwear were soaked with exudate, the patient's bedding was soaked or traces of exudate were present on the bedding; "moderate" if the dressing was soaked with exudate, the patient's underwear was soaked or traces of exudate were present on the underwear. The level of exudate was defined as "little" when the dressing was soaked, "no exudate" when traces of the exudate were present on the dressing but the dressing was not soaked.

According to the VAS scale, the pain and malodour level was defined as "strong" (VAS range 10-6.5), "moderate" (VAS range 3.5-6.0), "weak" (VAS 1.0-3.0) or "none" (VAS 0).

The combined presence of symptoms such as oedema of tissues surrounding the wound, erythema, increased local heat, purulent exudate and/or increased general body temperature was treated as a clinical sign of wound infection [7].

The wounds were rinsed with saline 3 times a day and covered with non-adherent silicone Na-Dressings (Systa- genix) and Sterilux EX (Hartmann) gauze bandages saturated with octenidine dihydrochloride. The above-mentioned sets were covered with absorbent Zetuvit (Hartmann) dressing and fixed to the healthy skin with Polofix (TZMO) adhesive plaster. All clinical assessments mentioned at the beginning of this section were repeated after 3 weeks of treatment.

\section{Bacteriological assessment}

At the baseline and after 3 weeks of treatment, the wounds were swabbed for microbiological assessment.

Transportation, incubation, isolation, drug susceptibility and resistance mechanisms of bacteria isolated from neoplastic ulcers were performed in the Department of Pharmaceutical Bacteriology, Poznan University of Medical Sciences.

\section{Qualitative assessments}

The tested material from transport media was incubated for $24-48 \mathrm{~h}$ at $37^{\circ} \mathrm{C}$ and inoculated by isolation method onto media enriched with 5\% sheep blood and onto selective-differentiating media: MacConkey medium (DIFCO, Germany), and Columbia agar with 5\% sheep blood, Streptosel, Chapman medium, pyocyanin medium, Sabouraud medium, Coccosel (all manufactured by bioMérieux (Marcy l'Etoile, France). Staphylococci were identified using the API Staph test, and Gram-negative rods using the Api 20E and Api 20NE tests, also by bioMérieux, France.

\section{Statistical analysis}

The results were analysed using statistical methods. The basic features such as gender of the patients, diagnosis, wound location, performance status of patients, amount of necrotic and granulating tissue, level of epithelialization and exudate, level of pain and malodour, were described using contingency tables and relevant percentage values. The following quantity features were analysed: time of ulcer duration, patients' body mass and BMI, number of strains isolated at the baseline and after 3 weeks of treatment. The above-mentioned features were analysed using non-parametric tests: Whitney-Mann test and Kruskal-Wallis test with multiple comparison. Quantity features were described using arithmetic mean $(X)$, standard deviation (SD), median (Me) and minimal (min.) and maximal (max.) value.

The correlations between quantity features were analysed using Fisher-Freeman-Halton test or Fisher exact test. The significance level was defined as $\alpha=0.05$.

\section{Results}

\section{Clinical assessments}

Thirty patients with neoplastic ulcers were included in the study. The clinical assessment included 30 patients at 
Table 2. Clinical changes in neoplastic ulcers at the baseline and after 3 weeks of treatment

\begin{tabular}{lcccc}
\hline $\begin{array}{l}\text { Clinical assessment } \\
\text { of the wound }\end{array}$ & Clinical status & $\begin{array}{c}\text { Baseline of the study } \\
\text { Number of wounds }(n=30)\end{array}$ & $\begin{array}{c}\text { End of the study } \\
\text { Number of the wounds }(n=25)\end{array}$ & $\begin{array}{c}\text { Statistic } \\
\text { significance }\end{array}$ \\
\hline Necrotic tissue & Significant & 13 & 0 & $p<0.05$ \\
amount & Moderate & 6 & 8 & $(p=0.000581)$ \\
& Low & 2 & 6 & 11 \\
\hline Lack & 9 & 15 & 0 & $p<0.05$ \\
& Significant & 8 & 8 & $(p=0.000089)$ \\
& Moderate & 7 & 15 & $p<0.05$ \\
& Low & 0 & 2 & $(p=0.001474)$ \\
\hline Pain level & Lack & 7 & 0 & $p<0.05$ \\
& Significant & 10 & 8 & $(p=0.001474)$ \\
& Moderate & 6 & 8 & \\
\hline Lalodour level & Lack & 7 & 9 & 0 \\
\end{tabular}

Table 3. Strains isolation at the beginning of study

\begin{tabular}{lcc}
\hline $\begin{array}{l}\text { Number } \\
\text { of isolated strains }\end{array}$ & $\begin{array}{c}\text { Number } \\
\text { of patients }\end{array}$ & Percentage \\
\hline 2 & 6 & 20 \\
\hline 3 & 12 & 40 \\
\hline 4 & 12 & 40 \\
\hline Together & 30 & 100 \\
\hline
\end{tabular}

the baseline and 25 patients after 3 weeks of the treatment, because 3 patients died before the $21^{\text {st }}$ day of the study and 2 patients were discharged, where they remained under home hospice care. The changes in all measured clinical parameters were observed.

The amount of necrotic tissue at the baseline was "significant" in 13 patients, "moderate" in 6 patients and "low" in 2 patients. After 3 weeks of the treatment, the amount of necrotic tissue was not "significant" in any patients; "moderate" in 8 patients, "low" in 6 patients. The drop in the amount of necrotic tissue was statistically significant $(p<0.05)$.

The level of exudate at the baseline was "high" in 15 patients, "moderate" in 8 patients and "low" in 7 patients. After 3 weeks of treatment, there were no patients with a "high" level of exudate; a "moderate" level of exudate was observed in 8 patients and a "low" level in 15. The decrease in the exudate level was statistically significant $(p<0.05)$.

The level of pain was described as "strong" by 7 patients at the baseline, "moderate" by 10 patients and "low" by 6 patients. 7 patients felt no pain. After 3 weeks of treatment, 9 patients felt no pain, 8 patients felt pain they described as "moderate" and 8 patients felt a "low" lev- el of pain. The decrease in pain felt by patients was statistically significant $(p<0.05)$.

Malodour at the baseline was assessed as "significant" in 3 patients, "moderate" in 4 patients, "low" in 7 patients, while the wounds of 16 patients secreted no malodour. After 3 weeks of treatment, no wounds secreted "significant" malodour, malodour was assessed as "moderate" in the case of 3 patients, and no malodour was felt in the case of 19 patients. The decrease in the level of malodour was statistically significant $(p<0.05)$. The results obtained are presented in Table 2.

Because no patient developed signs of clinical infection, there was no need for an antibiotic therapy. The longest time of treatment according to the presented scheme was 17 weeks. The death of 5 patients was a result of cancer progression.

\section{Bacteriological assessment}

Fifty-three Gram(-) and Gram(+) bacterial strains were isolated from the ulcers at the beginning of the treatment. Between 2 and 3, sometimes 4 strains were found in each of the malignant ulcers.

In 6 patients (20\%), 2 bacterial strains from ulcer were isolated, in 12 patients (40\%), 3 strains from ulcer were isolated and in 12 patients (40\%), 4 strains from ulcers were isolated. The results are shown in Table 3.

Among Gram(+) bacteria, S. aureus, found in 14 wounds (26.4\%), was the most dominant. Coagulase negative Staphylococci (CNS) were isolated less frequently: S. epidermidis was found in 5 wounds (9.4\%) and Staphylococcus sciuri in one wound (1.9\%). Enterococci were isolated sporadically, all isolated enterococci belonged to the Enterococcus faecalis species and these bacteria were found in 7 wounds (13.2\%). 
Enterobacteriaceae were most commonly isolated $\operatorname{Gram}(-)$ bacteria, principally Escherichia coli, isolated from 9 wounds (17\%) and Proteus mirabilis isolated from 7 wounds (13.2\%). Klebsiella pneumoniae was isolated from 1 wound $(1.9 \%)$, Serratia marcescens was isolated from 2 wounds (3.8\%). Non-fermentative Gram(-) bacteria were isolated less frequently: Pseudomonas aeruginosa from 5 wounds (9.4\%), Pseudomonas fluorescens and Stenotrophomonas maltophilia were isolated from one wound (1.9\%).

The frequency of occurrence of bacterial strains isolated at the baseline of the treatment is given in Table 4.

\section{End of the treatment}

After 3 weeks of treatment, in 20 patients (80\%), complete eradication of Gram(+) cocci of Staphylococcus species and Gram(-) Proteus mirabilis species was observed. In 5 patients, the use of the treatment procedures decreased bacterial flora to only one species. The relevant results are given in Table 5.

In 2 patients, the number of species was reduced from 3 to 1 species - Enterococcus faecalis. This bacterial species was isolated from the wound at the beginning and after the end of the treatment. In 2 patients, Gram(-) rods of Escherichia coli species were isolated at the beginning and after the treatment period. In 1 patient, non-fermentative Gram(-) rods of Proteus aeruginosa species were isolated at the baseline and after treatment. Statistical analysis of the changing number of bacteria species treated with octenidine dihydrochloride revealed that the observed reduction of bacterial strains number was statistically significant $(p<0.001)$.

The species of bacteria which persisted treatment are given in Table 6 . Some of the 53 isolated bacterial strains were considered alarm pathogens according to the State Centre of Drug Resistance of Microorganisms [8]. The type and percentage of alarm pathogens are given in Table 7 . As shown in Table 7, 11 out of 53 strains isolated from the wounds produced resistance mechanisms and therefore they were included in the group of alarm pathogens. Alarm pathogens with particular mechanisms of resistance isolated from ulcers after treatment are given in Table 8.

\section{Safety}

No serious adverse or side effects were observed in the course of the treatment. Eight patients (16\%) complained about temporary itching in the peri-wound area, while 3 of them developed erythema there. However, the abovementioned symptoms did not require any preventive steps or stopping the treatment. No signs of infection were observed and no antibiotics were used in the course of study.

\section{Discussion}

\section{Clinical aspects}

Neoplastic ulcers are considered hard-to-heal chronic wounds. Because of the progressive nature of the neo-
Table 4. Species and frequency of occurrence of bacteria isolated at the baseline of study $(n=53)$

\begin{tabular}{lcc}
\hline Bacterial species & $\begin{array}{c}\text { Number } \\
\text { of strains }\end{array}$ & $\begin{array}{c}\text { Percentage } \\
\text { of strains }\end{array}$ \\
\hline Gram(+) & 27 & 50.9 \\
\hline Staphylococcus aureus & 14 & 26.4 \\
\hline Staphylococcus epidermidis & 5 & 9.4 \\
\hline Staphylococcus sciuri & 1 & 1.9 \\
\hline Enterococcus faecalis & 7 & 13.2 \\
\hline Gram(-) & 26 & 49.1 \\
\hline Escherichia coli & 9 & 17.0 \\
\hline Proteus mirabilis & 7 & 13.2 \\
\hline Serratia marcescens & 2 & 3.8 \\
\hline Klebsiella pneumoniae & 1 & 1.9 \\
\hline Pseudomonas aeruginosa & 5 & 9.4 \\
\hline Pseudomonas fluorescens & 1 & 1.9 \\
\hline Stenotrophomonas maltophilia & 1 & 1.9 \\
\hline Total & 53 & \\
\hline
\end{tabular}

Table 5. Isolation of strains from neoplastic ulcers at the end of the treatment

\begin{tabular}{lcc}
\hline $\begin{array}{l}\text { Number } \\
\text { of strains }\end{array}$ & $\begin{array}{c}\text { Number } \\
\text { of patients }\end{array}$ & $\begin{array}{c}\text { Percentage } \\
\text { of patients }\end{array}$ \\
\hline No strains & 20 & 80 \\
\hline 1 & 5 & 20 \\
\hline Total & 25 & 100 \\
\hline
\end{tabular}

Table 6. Persistent bacterial flora isolated from neoplastic ulcers

\begin{tabular}{lcc}
\hline $\begin{array}{l}\text { Patient } \\
\text { number }\end{array}$ & $\begin{array}{c}\text { Beginning } \\
\text { of treatment }\end{array}$ & After 3 weeks \\
\hline 4 & $\begin{array}{c}\text { Escherichia coli } \\
\text { Enterococcus faecalis } \\
\text { Pseudomonas aeruginosa }\end{array}$ & $\begin{array}{c}\text { Enterococcus } \\
\text { faecalis }\end{array}$ \\
\hline 14 & $\begin{array}{c}\text { Enterococcus faecalis } \\
\text { Staphylococcus aureus } \\
\text { Escherichia coli }\end{array}$ & $\begin{array}{c}\text { Enterococcus } \\
\text { faecalis }\end{array}$ \\
\hline 17 & Pseudomonas aeruginosa & Pseudomonas \\
& aeruginosa \\
\hline 21 & Escherichia coli & Escherichia coli \\
\hline 23 & Escherichia coli & Escherichia coli \\
&
\end{tabular}


Table 7. Alarm pathogens isolated from the neoplastic ulcers at baseline assessment $(n=53)$

\begin{tabular}{lcc}
\hline $\begin{array}{l}\text { Number } \\
\text { of strains }(n)\end{array}$ & Percentage \% & $\begin{array}{c}\text { Resistance } \\
\text { mechanism }\end{array}$ \\
\hline $\begin{array}{l}\text { Staphylococcus aureus } \\
(n=2)\end{array}$ & 3.8 & MRSA \\
\hline $\begin{array}{l}\text { Enterococcus faecalis } \\
(n=2)\end{array}$ & 3.8 & HLAR \\
\hline $\begin{array}{l}\text { Enterococcus faecalis } \\
(n=6)\end{array}$ & 11.3 & $\mathrm{ES} \beta \mathrm{L}$ \\
\hline $\begin{array}{l}\text { Pseudomonas aeruginosa } \\
(n=1)\end{array}$ & 1.9 & $\mathrm{ES} \beta \mathrm{L}, \mathrm{M} \beta \mathrm{L}$ \\
\hline 11 & 20.8 & Total \\
\hline
\end{tabular}

Table 8. Alarm pathogens isolated from neoplastic ulcers after treatment with octenidine dihydrochloride $(n=5)$

\begin{tabular}{lcc}
\hline $\begin{array}{l}\text { Number } \\
\text { of strains }\end{array}$ & Species & $\begin{array}{l}\text { Resistance } \\
\text { mechanism }\end{array}$ \\
\hline 2 & Enterococcus faecalis & HLAR \\
\hline 2 & Escherichia coli & ES $\beta \mathrm{L}$ \\
\hline 1 & Pseudomonas aeruginosa & $\mathrm{M} \beta \mathrm{L}, \mathrm{ES} \beta \mathrm{L}$ \\
\hline
\end{tabular}

plasm, chances to heal the ulcer are low. Therefore, the procedures used serve first of all to alleviate the clinical symptoms and to improve the patient's quality of life.

The present study aimed to evaluate the impact of local administration of octenidine on the clinical condition of neoplastic ulcerations. The location of the patients' ulcers was similar to the one described in the literature $[9,10]$.

According to the best knowledge of the authors, there are no control trials concerning the effects of local use of antiseptics on the neoplastic ulcers. Only a small number of papers and case reports are available. Moreover, there are no original articles concerning the impact of antiseptic on the level of necrotic tissue which is the source of a potential infection, malodour and exudate from wound.

Contrary to many other types of chronic wounds, neoplastic ulcers are not suitable for surgical debridement because of the high risk of massive bleeding $[11,12]$. Therefore, some authors suggest that the removal of necrotic tissue should be performed by means of rinsing, with a warm solution of $0.9 \% \mathrm{NaCl}$ [13]. On the other hand, Carville used a $0.05 \%$ solution of chlorhexidine and $0.025 \%$ acetic acid for neoplastic ulcer rinsing [14]. Methods of autolytic debridement, using dressings ensuring a moist environment of the wound, are also described [15]. However, the authors point out to the risk of malodour increase under the occlusion. Young and Davis used hydrocolloid and hydrogel dressings to debride the ulcers, indicating that in the case of a high level of exudate, fre- quent changes of dressings are necessary [16]. The results of our study indicate that the use of octenidine hydrochloride leads to a statistically significant decrease in the necrotic tissue level. Moreover, the use of octenidine was not accompanied by side effects like trauma or bleeding from the wound.

There is a large number of papers concerning methods of management of exudate, malodour and pain. It seems that in the case of neoplastic ulcers, procedures developed for highly-exudating wounds, are most suitable. However, covering a neoplastic ulcer with an absorbent or even occlusive dressing might correlate with a higher risk of infection. Therefore, in this study, a different approach was adopted. The set of dressings used consisted of non-adherent silicone N/A dressing, gauze compresses soaked thoroughly with octenidine and covered with absorbent dressing.

It may be assumed, that the use of antiseptic would lead to decreased bacterial proteases activity and to a reduction in the exudate level [17]. However, no papers concerning the impact of antiseptics on the exudate level were found to confirm it. In a few papers, the use of polyurethane sponges and alginates for exudate management is described. Naylor underline the advantages of non-adherent dressings in the reduction of damage to sensitive tumour tissue [15]. Seaman suggests using dressings with petrolatum, covered with an absorbent dressing or even with the sanitary towels [18]. In the case of small ulceration with fistula, the use of a stomy set might be suitable [19]. In the case of highly-exudating ulcers, Dudner proposes using hydrofibre dressings [20]. However, his conclusions are based on case reports and not clinical trials. Longterm clinical observations of a large number of neoplastic ulcerations were conducted by Grocott [21]. In this trial, two systems were compared: occlusive gel pads (Novogel) covered with a membrane of high evaporation ability and an amorphous hydrogel (Innovative Technologies) covered with an absorbent dressing pad. The parameters of both sets of dressings were assessed by means of Teler ${ }^{\circledR}$ system. According to Grocott, good exudate management in neoplastic ulcers mainly depends on dressing fit and optimum absorption and venting of excess fluid. Subsequently, Grocott conducted a more detailed study including 8 different systems [22]. Two of them were found to be the most suitable: the first one was absorbing alginate or hydrofibre ${ }^{\circledR}$ covered with a polyurethane dressing with external, exudate-evaporating layer; the second one was nonadherent contact dressing soaked with silicon, covered with a secondary absorbent, exudate-evaporating dressing. This latter one is very similar to the set used in this study.

Another symptom that requires management in chronic wounds is the malodour caused by degradation of proteins of the necrotic tissue and the growth of bacteria. The pathogens responsible for the malodour may be anaerobic, such as Bacterioides spp. and Clostridium spp. The abovementioned anaerobic pathogens produce such chemical compounds as putrescine, kadawerine and short-chained fat- 
ty acids responsible for the particularly unpleasant smell [5]. Aerobic bacteria, inhabiting neoplastic ulcerations more frequently, e.g. Proteus spp., Klebsiella spp., Pseudomonas spp. are also responsible for the malodour, which however is not as strong as this produced by anaerobes. It is claimed that a synergistic coexistence of aerobic and anaerobic bacteria causes the strongest malodour [23-25]. As there is no standard assessment tool, malodour estimation is always a very subjective matter [26]. In our study, a visual analogue scale (VAS) was used for malodour assessment. This scale was also used in the study by Bower et al. [27].

According to Grocott [22], malodour should be managed by means of systemic or local application of metronidazole and/or antiseptics and the use of activated carbon dressings. The reduction of necrotic tissue level allows better penetration of the antiseptic into the ulceration and decreases the malodour level.

Although orally administered metronidazole helps to decrease malodour, its use may lead to the development of bacterial resistance and side effects such as nausea, vomits and symptoms of peripheral neuropathy after a longer period of use [28]. Therefore, the use of antibiotics is recommended only if clinically obvious symptoms of wound infection occur including erythema, swelling of wound-surrounding tissues, increase in exudate, malodour and general body heat [7]. In our study, no clinical signs of wound infection were observed in the treated patients, therefore no systemic antibiotic therapy was administered.

Although there are a few studies concerning the local use of metronidazole gel, only one of them is a prospective, randomized, double-blinded trial. The results of this trial indicate that the use of metronidazole gel decreases the malodour level. However, the observed trend was statistically insignificant [27]. A more recent trial showed that locally applied metronidazole is safe, efficient in the elimination of malodour and less toxic in comparison to systemic-administered metronidazole. However, the value of the above-mentioned trials is limited because of a low number of patients involved, no control group and a low level of statistical analysis [2]. There are also other clinical observations indicating the suitability of locally administered honey, sugar paste and silver sulfadiazine salt [29]

In our study, the use of octenidine dihydrochloride led to a statistically significant decrease in malodour during 3 weeks of treatment. Unfortunately, these results cannot be compared to other studies as there is no other available research concerning the use of antiseptics in malodour management. Nonetheless, positive changes of clinical symptoms observed in our study were statistically significant. Furthermore, no side effects, such as bleeding and pain during dressing change, were observed. These positive effects are related to the impact of octenidine on the improvement of the ulcer clinical status and reduction in the necrotic tissue.

Another important factor in the treatment of neoplastic ulceration is the pain level. It may be deep somatic pain, neuropathic pain or incidental pain related to the wound care and dressing change. To avoid incidental pain, fastacting analgesics (administered orally, subcutaneously or intravenously) may be administered. In the present study, analgesics dosage depended on the level of pain caused by the neoplasm. Therefore, changes of dressings did not require additional administration of analgesics. During the treatment period, the level of pain caused by the wound has decreased in a statistically significant manner. Although the mechanism of this phenomenon remains unclear, it can be speculated that the decrease in pain may be owed to the provision of moist environment and/or a direct use of non-adherent silicone dressing on the wound (N/A dressing plus). The above-mentioned phenomenon requires further studies. However, these pilot results may indicate the right direction to proceed.

\section{Microbiological aspect}

Apart from the assessment of the clinical status of neoplastic ulcers, microbiological assessments were also performed.

In the treated neoplastic ulcers, Gram(-) bacterial flora of the Enterobacteriaceae family has dominated.

The composition of bacterial flora isolated from neoplastic ulcers was similar to the one described by other authors [30]. Gram(-) rods found commonly in the ulcers were most probably the natural gut flora of the patients. It is well known that gut flora transferred from natural habitat to wounds may be an etiological factor of bacteraemia and a destruction of host tissue. In exceptional situations, like tumor or diabetes, saprophytic bacterial flora is able to cause symptomatic infections. It has to be remembered that the state of bacterial colonization does not support the treatment. Moreover, when antibiotic therapy is applied (e.g. when bacterial colonization changes into infection), it may lead to a selection of multi-resistant bacterial strains with different resistance mechanisms, responsible for many types of nosocomial infections [31]. Among the most essential resistance mechanisms in Gram(-) rods of Enterobacteriaceae family is the ability to produce extended-spectrum $\beta$-lactamases (ES $\beta$ L). These are enzymes able to hydrolyse penicillins and cephalosporins (with the exception of cefamycins and monobactams). Enterobacteriaceae ES $\beta$ L-positive strains are considered alarm pathogens. Such strains were isolated from 4 neoplastic ulcers. In 2 ulcerations, two ES $\beta$ L-positive E. coli strains persisted the treatment. These strains were isolated in vulva area ulcers, invading the anus, contaminated with stool and therefore particularly hard to care.

The ability of octenidine to efficiently eradicate multiresistant strains, incl. alarm pathogens is of paramount importance not only for the process of wound treatment and management, but also for the limitation of nosocomial infections, including sepsis and other life-threatening bacterial diseases. Unfortunately, it is not possible to compare the obtained results to other trials as there is no 
available research concerning the corresponding type of combined treatment.

Coagulase-negative and Coagulase-positive cocci were the second, by frequency, type of bacteria found in neoplastic ulcers. These results are similar to these reported by other authors [30].

In the present study, the application of octenidine and dressings led to $100 \%$ eradication of both coagulase-negative and coagulase-positive types of cocci from the neoplastic ulcers. The authors found only 4 studies on the use of octenidine for skin decolonization of methicillin-resistant S. aureus (MRSA). The efficacy of the treatment was $6-75 \%[31,32]$. These results cannot be compared with the results of this study because the methods used and the purpose differed diametrically.

In a recently published comparative investigation, antimicrobial efficacy of antiseptics: PVP-iodine, triclosan, chlorhexidine, octenidine and polyhexanide used for presurgical antisepsis and antiseptic treatment of the skin, wounds and mucous membranes, was tested. The minimal inhibiting concentration (MIC) of each antiseptic was assessed for S. aureus, E. faecalis, S. pneumoniae, E. coli and $P$. aeruginosa. Minimal inhibiting concentration of octenidine displayed the highest activity for the tested strains (16-23 mg/l). According to the authors of the investigation, octenidine is the most suitable antiseptic if prolonged contact time or immediate effect is feasible [33]. In vitro trials performed by Samet et al. indicate high antimicrobial efficacy of octenidine against drug-resistant bacteria isolated from various clinical samples. 99.999\% reduction of bacterial count in suspension in 1-min contact time was achieved for all tested strains [34], including the already discussed rods of the Enterobacteriaceae family. The results of Samet and of our study show the ability of octenidine to completely eradicate staphylococci strains. Therefore, octenidine seems to be a very potent tool in a fight against these bacterial species. Owing to its ability to reduce the microbiological count in the wound and to prevent the wound infection, octenidine allows to limit the application of antibiotics. It is particularly important because excessive use of these antimicrobials is correlated with a spread of antibiotic-resistant strains. In this study, only bacteriafree wounds were considered "healed" for the purposes of a statistical analysis.

Another bacterial species isolated from neoplastic ulcers was Gram(+) coccus, E. faecalis. This bacterial species is regarded as the natural gut flora of humans. Until recently, this species has not been associated with high virulence. However, broad application of cephalosporins led to the spread of $E$. faecalis as these bacteria display an intrinsic resistance against this class of antibiotics. Presently, E. faecalis is considered third or even second etiological factor of nosocomial infections. Two of them were alarm pathogen strains, displaying the HLAR (High Level of Aminoglycoside Resistance) mechanism. These strains are included in the list of nosocomial alarm pathogens [8]. Octenidine's effi- cacy against the above-mentioned bacteria colonizing neoplastic ulcers was $83.3 \%$. A reduction in number of strains was statistically significant. The use of octenidine for wound treatment decreased bacterial count and prevented possible infection. Again, the lack of similar clinical studies makes comparison of results impossible.

The last, numerous group of microorganisms found in neoplastic ulcers were non-fermentative Gram(-) rods of Pseudomonas spp. and Acinetobacter spp.

Pseudomonas rods are considered dangerous not only because of their intrinsic resistance mechanisms, but also because of the easiness with which they survive and spread in different environmental conditions. Pseudomonas strains are also able to produce ES $\beta$ L enzymes which give these bacteria resistance against penicillin, cephalosporins (incl. III and IV generation cephalosporins) and monobactams. The efficacy of octenidine in the eradication of this group of bacteria was $83.3 \%$.

The microbiological research conducted in this work reveals the importance of screening for pathogens colonizing chronic wounds and of assessing bacterial resistance mechanisms. Such procedures allow to verify empirical antibiotic therapy and to prevent the spread of antibiotic-resistance strains [31].

The lack of basic microbiological knowledge and underestimation of importance of microbiological assessment are often the reasons for therapeutic failures. Misuse of antibiotics and chemotherapeutics is one of the main reasons why bacterial antibiotic resistance increases. The scheme of treatment used in this study allowed to control the microbiological status of neoplastic ulceration and may be an alternative for antibiotics and chemotherapeutics in the management of bacterial colonization - even if the wound is colonized by alarm pathogens.

Besides the ability to efficiently reduce bacterial count, an appropriate antiseptic should display minimal cytotoxic effect. Müller and Kramer introduced a value referred to as "Biocompatibility Index" (BI), used for comparative assessments of antiseptics. Biocompatibility Index $>1$ is typical of antiseptics displaying high antimicrobial activity and low cytotoxicity against healthy tissues. Assessments of the impact of different antiseptics on E. coli and S. aureus in the presence of fibroblast cell line showed that the optimal value of BI was achieved for octenidine [35].

Because the available "high quality data" concerning the use of antiseptics in the treatment of chronic wounds are rather scant, there is no doubt that an urgent need exists for controlled, randomized, prospective trials concerning this subject [36]. The results of these trials may allow clinicians to eliminate obsolete, but still "in use" antiseptics having a harmful effect on the healthy tissues and displaying an uncertain influence on bacteria.

The results presented and discussed in this study indicate the suitability of the applied scheme in the treatment of neoplastic ulcers. The improved clinical status of the 
wounds attributed to octenidine's antimicrobial efficacy (also against multi-resistant strains) no doubt constitutes progress that sheds new light on the therapy of neoplastic ulcerations.

\section{Conclusions}

The used scheme of treatment is efficient and brings clinical improvement. During the 3-week treatment, reduction of necrotic tissue and decrease in the level of exudate, pain and malodour were observed in all patients. High activity of octenidine against Gram(-) and Gram(+) bacteria was observed. The use of octenidine dihydrochloride correlated with a progressing eradication of multiresistant strains and alarm pathogens. No serious adverse effects or significant symptoms of intolerance of the applied treatment were observed.

\section{Acknowledgments}

I am grateful to Higiena company for giving medical probes for the treatment of chronic ill patient. We are grateful to all nurse staff from Hospice Palium for help with caring for patients.

No specific funding for this study has been received and the study was a part of our novel method of treatment. This study was supported by a grant for its own study from the University of Medical Science, Poznan No. 502-01-01114157-06748.

\section{References}

1. Ambrogi V, Nofroni I, Tonini G, et al. Skin metastases in lung cancer. Analysis of 10-year experience. Oncol Rep 2001; 8: 57-61.

2. Bale S, Tebble N, Price P. A topical metronidazole gel used to treat malodorous wounds. Br J Nurs 2004; 13 (11 suppl): 4-11.

3. Grocott $P$. The palliative management of fungating malignant wounds. J Wound Care 1995; 4: 240-2.

4. Moddy M. Metrotop: a topical antimicrobial agent for malodour wounds. Br J Community Nurs 1998; 3: 202-5.

5. Thomas S, Fisher B, From PJ, Waring MJ. Odour-absorbing dressing. J Wound Care 1998; 7: 246-50.

6. Doyle D, Hanks GWC, MacDonald N (eds). Oxford textbook of palliative medicine. Oxford University Press, Oxford 1998; 203-19.

7. Cutting KF, Harding KG. Criteria for identifying wound infection. J Wound Care 1994; 3: 198-201.

8. Regulation Ministry of Health in the process of registration of capital infections and reporting them dated 11.03.2005. Dziennik Ustaw 2005, 54; poz. 484.

9. Lookingbill DP, Spangler N, Sexton FM. Skin involvement as the presenting sign of internal carcinoma. J Am Acad Dermatol 1990; 22: 19-26.

10. Seaman S. Management of malignant fungating wounds in advanced cancer. Semin Oncolog Nurs 2006; 22: 185-93.

11. Goode ML. Psychological needs of patients when dressing a fungating wound: a literature review. J Wound Care 2004; 13: $380-2$.

12. Lewandowicz E, Witmanowski H, Sobieszek D. Selection of surgical technique in treatment of pressure sores. Postep Derm Alergol 2011; 28: 23-9.
13. Watret L, Armitage M. Making sense of wound cleansing. J Common Nurs 2002; 16: 27-34.

14. Carville K. Caring for cancerous wounds in the community. J Wound Care 1995; 4: 66-8.

15. Naylor W. Using a new foam dressing in the care of fungating wounds. Br J Nurs 2001; 10: 24-30.

16. Davies A. Nursing a patient with malodorous fungating nonhealing wound. Nurs Times 2003; 99: 58-60.

17. Sopata M, Tomaszewska E, Machyńska-Bućko Z, KotlińskaLemieszek A. Modern methods of conservative treatment of pressure ulcers. Postep Derm Alergol 2012; 29: 40-6.

18. Seaman S. Dressing selection in chronic wound management J Am Podiatr Med Assoc 2002; 92: 24-33.

19. Bonton P, Parslow N. Malignant wounds: holistic assessment and management. In: Chronic wound care: a clinical sourcebook for healthcare professionals. Krasner PL, Rodeheaver GT, Sibbald RG. (eds). HMP Communications 2001; 699-710.

20. Dudner R. The management of patients with fungating or malignant wound. J Community Nurs 1998; 12: 30-4.

21. Grocott P. Exudate management in fungating wounds. J Wound Care 1998; 7: 445-8.

22. Grocott P. The palliative management of fungating malignant wounds. J Wound Care 2000; 9: 4-9.

23. Bowler PG, Davies BJ, James SA. Microbial involvement in chronic malodour wound. J Wound Care 1999; 8: 216-8.

24. Konecka-Matyjek E, Maćkiw E, Krygier B, et al. National monitoring study on microbial contamination of food-contact surfaces in hospital kitchens in Poland. Ann Agric Environ Med 2012; 19: 457-63.

25. Noworyta-Głowacka J, Bańkowski R, Siennicka J, et al. Influence of chlorpyrifos on the profile of subpopulations of immunoactive cells and their phagocytic activity in an experimental in vivo model. Ann Agric Environ Med 2012; 19: 483-6.

26. Moore Z, Pitman S. Towards establishing a pressure sore prevention and management policy in an acute hospital setting. Irleand J Nursing Midwifery 2000; 1: 7-11.

27. Bower M, Stein R, Evans TR, et al. A double-blind study of the efficacy of metronidazol gel in the treatment of malodorous funganting tumours. Europ J Cancer 1992; 28A: 888.

28. Hampson JP. The use of metronidazole in the treatment of malodorous wounds. J Wound Care 1996; 5: 421-5.

29. Benbow M. Malodorous wounds: how to improve quality of life. Comm Nurse 1999; 5: 43-6.

30. Dissemond J, Schmid EN, Esser S, et al. Bakterielle Kolonisation chronischer Wunden. Hautarzt 2004; 55: 280-8.

31. Dzierżanowska D. Practical antibiotherapy. $\alpha$-medica press, Bielsko-Biała 2000; 18-30.

32. Krishna BV, Gibb AP. Use of octenidine dihydrochloride in methicilin-resistant Staphylococcus aureus decolonisation regimens: a literature review. J Hosp Infect 2010; 74: 199-203.

33. Koburger T, Hubner NO, Braun M, et al. Standarized comparision of antiseptic efficacy of triclosan, PVP-iodine, octenidine dihydrochloride, polyhexanide and chlorxexidine dicgluconate. J Antimicrob Chemiother 2010; 65: 1712-9.

34. Samet A, Bronk M, Kur J. Octenisept - an effective antiseptic to resistant bacteria. Zakażenia 2003; 1: 92-93.

35. Muller G, Kramer A. Biocompatibility index of antiseptic agents by parallel assessment of antimicrobial activity and cellular cytotoxicity. J Antimicrob Chemother 2008; 61: 1281-7.

36. Gottrup F, Apelqvist J, Price P. Outcomes in controlled and comparative studies on non-healing wounds: recommendations to improve the quality of evidence in wound management. J Wound Care 2010; 19: 237-68. 